\title{
Investigation of the Health Literacy Level of Women in Reproductive Age as a Public Health Problem in Zahedan
}

\author{
Marzieh Rakhshkhorshid ${ }^{1 *}$, Ameneh Safarzadeh Sarasiyabi ${ }^{1}$ \\ 'Department of Nursing and Midwifery, Pregnancy Health Research Center, Zahedan University of Medical Sciences, \\ Zahedan, Iran
}

\author{
*Correspondence to \\ Marzieh Rakhshkhorshid; \\ Department of Midwifery, Nursing \\ and Midwifery Collage, Mashahir \\ Square, Zahedan, Iran. \\ Tel/Fax: +985433442481 \\ Email: \\ Marzieh.rakhshkhorshid@gmail.com
}

Received March 26, 2017

Accepted June 25, 2017

Published online June 30, 2017

\begin{abstract}
Introduction: The aim of this study was to evaluate health literacy $(\mathrm{HL})$ status among women of reproductive age who referred to urban health centers in Zahedan.

Methods: In this cross-sectional descriptive study, 250 women of reproductive age (15-49 years old) who referred to urban health centers in Zahedan, Iran were assessed using the Iranian Health Literacy Questionnaire. To analyze the data, SPSS 15 software and statistical tests including independent sample t test and chi-square test were used.

Results: The mean \pm standard deviation (SD) age of participants in this study was $26.32 \pm 5.83$ with a minimum of 15 and maximum of 45 years. The majority of the participants $(32.4 \%)$ held a high school diploma and $88.8 \%$ of them were housewives. The mean HL score was computed 7.15 out of 20 indicating that $100 \%$ of the participants had inadequate HL. There were significant relationships between $\mathrm{HL}$ score and age, occupation, educational degree, language and living location $(P<0.05)$.

Conclusion: Considering high levels of inadequate $\mathrm{HL}$ among women of reproductive age in Zahedan, it is recommended to use $\mathrm{HL}$ measures to screen people with inadequate $\mathrm{HL}$, to provide each individual with information and services which are appropriate to their HL skills and to be able to reduce the consequences of inadequate HL.

Keywords: Health literacy, Iran, Women, Iranian Health Literacy Questionnaire
\end{abstract}

Please cite this article as follows: Rakhshkhorshid M, Safarzadeh Sarasiyabi A. Investigation of the health literacy level of women in reproductive age as a public health problem in Zahedan. Int J Basic Sci Med. 2017;2(2):101105. doi:10.15171/ ijbms.2017.19.

\begin{abstract}
Introduction
Every day millions of people have to make decisions about the health issues surrounding themselves, their family and their community. ${ }^{1}$ The ability of individuals to seek, understand and use health information are called health literacy (HL). ${ }^{2}$ The World Health Organization (WHO) has introduced HL as one of the most important determinants to promote various aspects of public health. ${ }^{3}$ It is defined as cognitive and social skills which determine the motivation and ability of individuals to access, understand and use information in a way that is conducive to maintaining and improving their health. ${ }^{4}$ Low health literacy has been introduced by many researchers as a global problem and a challenge in the 21 st century. ${ }^{5,6}$ People with strong HL skills enjoy better health and well-being, while
\end{abstract}

those with weaker HL skills tend to engage in riskier behavior and have poor health. ${ }^{7}$ Inadequate HL can increase the burden of disease on society. ${ }^{8}$

Since women play an important role in training, maintaining and improving their own and their family members health and subsequently can influence society's health, ${ }^{9}$ more attention should be paid to increase their HL. ${ }^{10}$ Without an adequate understanding of health care information, it would be difficult for a woman to make informed decisions leading to better health outcomes for herself and her family. Thus, health literacy is an essential factor in a woman's ability to understand, process and act on health-related information. ${ }^{11}$

In a study conducted on HL among Spanish-Latino speaking parents with little English proficiency, results revealed that

\footnotetext{
Copyright $\odot 2017$ The Author(s); Published by Zabol University of Medical Sciences. This is an open-access article distributed under the terms of the Creative Commons Attribution License (http://creativecommons.org/licenses/by/4.0), which permits unrestricted use, distribution, and reproduction in any medium, provided the original work is properly cited.
} 
mothers with higher HL skills are more likely to administer the correct amount of medication to a child. ${ }^{12}$ The result of Kohan et al study about the association of HL with prenatal care and pregnancy outcome indicated that women with higher HL have begun prenatal care earlier and have more frequently referred for health care compared to women with low HL. ${ }^{13}$

Given the importance of HL, its impact on women's health, and differences in ethnicity and language in Sistan and Baluchistan province with other parts of the country, it seemed necessary to evaluate the HL. Hence the current study aimed at determining the HL level and its related factors in women of reproductive age.

\section{Methods}

This cross-sectional descriptive study conducted from September to November 2015, for the women of reproductive age who referred to health centers in Zahedan. In this study, a stratified cluster sampling was used. At first the city was divided into 5 geographical regions including North, South, East, West and Center and then a city health clinic was selected randomly by drawing from the list of urban health centers in each district of the city. After that, 50 females were selected from each health center by convenience sampling. The inclusion criteria were the being able to read and write, having Iranian citizenship, not being pregnant, and being at the minimum age of 15 years and the maximum age of 49 years. The exclusion criteria were unwillingness to participate in the study and failure to complete the questionnaire.

The sample size of 247 was calculated using the following formula based on a previous study, ${ }^{14}$ and taking into account the $95 \%$ confidence level, $d=4.5$ and $S=36.1$.

$$
n=\frac{\left(Z_{1-\frac{\alpha}{2}}\right)^{2}(S)^{2}}{(d)^{2}}
$$

Data collection instrument included a demographic information form (age, marital status, education, occupation, dialect or the language used at home), and Iranian Health Literacy Questionnaire (IHLQ). The questionnaire was designed by the Health Modeling Center associated with Kerman University of Medical Sciences to evaluate HL in Persian speaking adults and was approved in terms of reliability and validity in a national research project. ${ }^{15}$ In the current study, for the sake of content validity, a number of subject-matter experts were asked to decide how well the questions measure the HL. Cronbach a for IHLQ was calculated 0.92 in this study. IHLQ contains 9 sub-components which are as follows: access to health information sources (5 items), using of these sources (6 items), the ability to read ( 5 items), the ability to understand (8 items), the judgment and assessment (6 items), the ability to make decisions and communications ( 8 items), health knowledge (5 items), individual empowerment (8 items) and social empowerment (4 items). In order to determine HL score, each sub-component score was calculated separately and then was multiplied by the number of questions of the same sub-component. Ultimately, sum of the com- ponents scores was divided by the total number of questions (55 items) to obtain the total score. The final score of HL was based on a 0 to 20 scale, in which less than 10,10 to 14 and more than 14 was considered limited, marginal and adequate health literacy, respectively.

A total of 250 demographic information forms and questionnaires were provided to the eligible people after explaining study objectives and obtaining the written consent.

All the 250 distributed forms and questionnaires were completed in 30 minutes and returned. Descriptive statistics, independent $t$ test for continuous variables and chisquare test for categorical variables were used to analyze the data. SPSS version 15 was used for statistical analysis; $\alpha=0.05$ was considered as the level of statistical significance.

\section{Results}

According to the results, the mean \pm standard deviation (SD) of age in these participants was $26.32 \pm 5.83$ years old with a minimum of 15 and maximum of 45 years and the majority held a diploma (32.4\%), were married (92\%) and were housewives $(88.8 \%)$. The average HL score was limited ( 7.15 out of 20 ), and $100 \%$ of patients had inadequate HL. Table 1 shows the demographic characteristics of the participants based on the health literacy level.

Table 2 indicates the average raw score of health literacy in each sub-component.

Comparison of health literacy level in health centers

Table 1. Demographic and Background Characteristics, by Health Literacy Level

\begin{tabular}{|c|c|c|c|}
\hline Characteristics & $\begin{array}{l}\text { Limited Health } \\
\text { Literacy } \\
\text { No. }(\%)\end{array}$ & $\begin{array}{l}\text { Marginal Health } \\
\text { Literacy } \\
\text { No. }(\%)\end{array}$ & $P$ Value \\
\hline Age $(y)$ & & & $<0.001$ \\
\hline $15-25$ & $112(44.8)$ & $3(1.2)$ & \\
\hline $26-35$ & $103(41.2)$ & $17(6.8)$ & \\
\hline $36-45$ & $9(3.6)$ & $6(2.4)$ & \\
\hline Ethnicity & & & 0.001 \\
\hline Fars & $88(35.2)$ & $19(7.6)$ & \\
\hline Balouch & $136(54.4)$ & $7(2.8)$ & \\
\hline Education & & & $<0.001$ \\
\hline Elementary school & $47(18.8)$ & $0(0)$ & \\
\hline Middle school & $37(14.8)$ & $0(0)$ & \\
\hline High school & $28(11.2)$ & $1(0.4)$ & \\
\hline Diploma & $71(28.4)$ & $10(4)$ & \\
\hline Associate degree & $20(8)$ & $6(2.4)$ & \\
\hline BA or higher degree & $21(8.4)$ & $9(3.6)$ & \\
\hline Job & & & $<0.001$ \\
\hline Housewife & $208(83.2)$ & $14(5.6)$ & \\
\hline Employed & $7(2.8)$ & $12(4.8)$ & \\
\hline Unemployed & $9(3.6)$ & $0(0)$ & \\
\hline Marital status & & & 0.409 \\
\hline Married & $205(82)$ & $25(10)$ & \\
\hline Single & $19(7.6)$ & $1(0.4)$ & \\
\hline
\end{tabular}


based on chi-square test was significant $(P<0.001)$. Table 3 shows the health literacy level of the participants disaggregated by urban health centers.

\section{Discussion}

The results showed that $100 \%$ of females of reproductive age had inadequate health literacy. The results of a study by Peyman et al on rural females in Roshtkhar, Razavi Khorasan province, Iran, showed that $88.8 \%$ of participants had inadequate health literacy. ${ }^{16}$ Also, the results of a study in Isfahan, Iran, by Kohan et al on females after childbirth showed that $82 \%$ of females had limited and marginal health literacy. ${ }^{13}$ These studies and the present study findings were in line with the results of the study conducted by Ghanbari et al on HL in pregnant mothers in Tehran, ${ }^{17}$ but the percentage of females who had inadequate health literacy $(54.6 \%)$ remarkably differed from those of the present study. It seems that the difference was due to different geographical regions, research population, and the questionnaires used in the studies. The study by Ghanbari et al indicated that access to information and benefiting from health care services were easier for people who live in Tehran, the capital, compared with the ones living in distant locations and underserved cities such as Zahedan. The present study population included females of reproductive age, while Ghanbari et al studied pregnant mothers who were likely more motivated, and paid more attention to health information and health recommendations. In addition, IHLQ used in the present study measures a wider scope, compared with other health literacy

Table 2. Average Health Literacy Raw Score in Each Sub-component

\begin{tabular}{lccc}
\hline Sub-component & $\begin{array}{c}\text { No. of } \\
\text { questions }\end{array}$ & $\begin{array}{c}\text { Score } \\
\text { Range }\end{array}$ & Mean (SD) \\
\hline Access to information sources & 5 & $0-5$ & $12.02(6.64)$ \\
Using Information & 6 & $0-6$ & $17.08(9.38)$ \\
Ability to read & 5 & $0-15$ & $44.52(13.17)$ \\
Ability to understand & 8 & $0-24$ & $120.73(36.15)$ \\
Judgment and assessment & 6 & $0-18$ & $67.2(21.61)$ \\
Ability to make decisions and & 8 & $0-16$ & $81.98(26.56)$ \\
communicate & 5 & $0-5$ & $12.86(6.74)$ \\
Health knowledge & 8 & $0-16$ & $26.11(30.42)$ \\
Individual empowerment & 4 & $0-8$ & $10.36(7.97)$ \\
Social empowerment & & &
\end{tabular}

Table 3. Health Literacy Level of the Participants Disaggregated by Urban Health Centers

\begin{tabular}{lcc}
\hline \multirow{2}{*}{ Urban Health Centers $^{\mathrm{a}}$} & \multicolumn{2}{c}{ Health literacy } \\
\cline { 2 - 3 } & $\begin{array}{c}\text { Limited } \\
\text { No. (\%) }\end{array}$ & $\begin{array}{c}\text { Marginal } \\
\text { No. (\%) }\end{array}$ \\
\hline Imam Javad & $50(100)$ & $0(0)$ \\
Imam Reza & $41(73)$ & $9(27)$ \\
Imam Hadi & $48(96)$ & $2(4)$ \\
Imam Hasan Mojtaba & $50(100)$ & $0(0)$ \\
Farokhi Sistani & $35(70)$ & $15(30)$ \\
\hline
\end{tabular}

a $P<0.001$. assessment questionnaires; e.g. Test of Functional Health Literacy in Adults (TOHFLA), which only examine the areas of reading and computation.

The current study findings showed that there was a significant relationship between $\mathrm{HL}$ and age $(P<0.001)$, and that the older a participant was, the higher HL she had. The results of the studies by Jovic-Vranes et $\mathrm{al}^{18}$, Berens et $\mathrm{al}^{19}$ and Peyman et $\mathrm{al}^{16}$ showed that with increasing the age, health literacy decreased. This difference could be due to the limited age range of the present study (15 to 45 years). In other words, the current study was conducted on a young population, while Jovic-Vranes et al and Peyman et al studied individuals aged 35 years or older. Our study conducted only in females of reproductive age but Berens et al studied all age groups in both genders.

The current study results showed that with increasing the years of education, HL increased, which was consistent with the results of several other studies conducted in this field. ${ }^{18,20}$ In the current study, despite the significance of the relationship between health literacy and years of education, even educated people with more than 12 years of education lacked enough health literacy. Thus, education can be a predictor of HL, but it is usually more complex, and often lower than people's general literacy. ${ }^{21}$

In the current study, there was a significant relationship between employment status and HL score. Employed females had higher HL than housewives or the unemployed ones. These results were in line with those of the studies by Jovic-Vranes et al, and Haghighi et al. ${ }^{3,18}$ In the current study, employed females had higher level of education, compared with housewives or unemployed females, which can be the reason for their higher HL. Several studies also showed that generally, people with high socioeconomic status had higher HL. ${ }^{14,22}$ It seems that other reasons for higher health literacy in employed females were a better economic status and financial independence.

In the current study, there was no significant relationship between marital status and HL score. The results of the present study were not consistent with those of Haghighi et al who examined the health literacy of females of reproductive age with breast cancer. ${ }^{3}$ The current study was conducted in health centers where the number of referring single people was usually low. Most services provided at health centers include pre-pregnancy counseling, care during pregnancy, postpartum care, child health care, child growth monitoring, and reproductive health services. Basically, single people rarely came to these centers, thus, it seems to be the reason why the study results were not statistically significant.

The results also showed that the HL score in adults who spoke Baluchi was significantly lower than that of the people who spoke Persian. In various studies, ethnicity and language were identified as the factors influencing HL. ${ }^{23-25}$ Health care providers in health centers spoke Persian and written sources of information and health recommendations were also provided in Persian. Differences in language are a barrier to effective communication. In addition, cultural differences, often associated with 
differences in language, are also communication barriers. ${ }^{26}$ Language barriers decrease access to primary care and preventive care, reduce individual's compliance with treatment, and lower one's satisfaction..$^{27}$

Comparison of HL mean scores in different urban health centers showed significant differences. The highest and lowest scores belonged to Farokhi-Sistani and Imam Hassan health centers, respectively. The mean age of patients referred to Farokhi-Sistani Health Center was higher than those of other centers. The number of people with more than 12 years of education in this health center was higher than those of the other centers (48\%). These results were consistent with the results of the study conducted by Ghanbari et al. Other studies conducted in this area also showed significant differences between HL level of people referred to rural and urban health centers as well as those of the ones referred to urban health centers and emergency units..$^{14,28,29}$

One of the strengths of this study was the use of Iranian native standard health literacy assessment tool which measures a wider scope of HL compared to the tools used in similar studies. The limitations of the study can be working hours of health centers and the type of services provided in them, because employed or single people were less likely to participate in the study.

\section{Conclusion}

The current study showed that females of reproductive age referred to health centers lack adequate HL. Considering the fact that health literacy is one of the most important components of increasing the level of public health, the results of the current study are alarming for the health system planners and policy makers. It is recommended to plan interventional programs to promote HL level of females with low socioeconomic level that belong to an ethnic minority, and live in deprived areas or countryside. It is also recommended to utilize HL assessment tools in health centers to screen people with inadequate HL, and provide education, prevention, treatment, and health promotion information and services in accordance with each person's HL level. Therefore, the consequences of inadequate health literacy can be reduced.

\section{Ethical Approval}

The study was approved by the ethics committee of Zahedan University of Medical Sciences (IR.ZAUMS.REC.1394.153). We obtained informed consent form our participants after explaining study objectives. Confidentiality of data was guaranteed by the researchers.

\section{Competing Interests}

The authors declare that they have no conflict of interest.

\author{
Acknowledgments \\ Special thanks to participants and respected staff of Urban \\ Health Centers in Zahedan.

\section{References} \\ 1. Nielsen-Bohlman L, Panzer AM, Kindig DA. Health
}

Literacy: A Prescription to End Confusion. Washington DC: National Academies Press (US); 2004.

2. Tique JA, Howard LM, Gaveta S, et al. Measuring health literacy among adults with HIV infection in Mozambique: development and validation of the HIV literacy test. AIDS Behav. 2017;21(3):822-832. doi:10.1007/s10461-0161348-3.

3. Haghighi ST, Lamyian M, Granpaye L. Assessment of the level of health literacy among fertile Iranian women with breast cancer. Electron Physician. 2015;7(6):1359-1364. doi:10.14661/1359

4. Riva S, Antonietti A, Iannello P, Pravettoni G. What are judgment skills in health literacy? A psycho-cognitive perspective of judgment and decision-making research. Patient Prefer Adherence. 2015;9:1677-1686. doi:10.2147/ PPA.S90207.

5. Lee SYD, Tsai TI, Tsai YW, Kuo KN. Health literacy, health status, and healthcare utilization of Taiwanese adults: results from a national survey. BMC Public Health. 2010;10:614. doi:10.1186/1471-2458-10-614.

6. Malekzadeh S, Azami M, Mirzaei M, Motamedi F. Comparative investigation of health literacy level of cardiovascular patients hospitalized in private and educational hospitals of Kerman city, Iran. Acta Inform Med. 2016;24(1):56-60. doi:10.5455/aim.2016.24.56-60.

7. Health Literacy. The Solid Facts World Health Organization (WHO). http://www.thehealthwell.info/node/534072. Updated July 1, 2013. Accessed May 18, 2017.

8. Shieh C, Halstead JA. Understanding the impact of health literacy on women's health. JOGNN. 2009;38(5):601-612. doi:10.1111/j.1552-6909.2009.01059.x.

9. Barooti E, Sadeghi N, Karimi-Zarchi M, Soltani HR. New results regarding trends in Iranian women's health and a comparison with WHO data. Clin Exp Obstet Gynecol. 2011;38(4): 390-393.

10. Ferguson B. Health literacy and health disparities: the role they play in maternal and child health. Nurs Womens Health. 2008;12(4);286-298. doi:10.1111/j.1751486X.2008.00343.x

11. Corrarino JE. Health literacy and women's health: challenges and opportunities. J Midwifery Womens Health. 2013;58(3):257-264. doi:10.1111/jmwh.12018

12. Leyva M, Sharif I, Ozuah PO. Health literacy among Spanish-speaking Latino parents with limited English proficiency. Ambulatory Pediatics. 2005;5(1):56-59.

13. Kohan S, Ghasemi S, Dodangeh M. Associations between maternal health literacy and prenatal care and pregnancy outcome. Iran J Nurs Midwifery Res. 2007;12(4):146-152.

14. Tehrani Banihashemi SA, Amirkhani MA, Haghdoost AA, et al. Health literacy and the affecting factors: a study in five provinces of Iran. Journal of Medical Education Development Center. 2007;4(1):1-9.

15. Haghdoost AA, Rakhshani F, Aarabi M, et al. Iranian Health Literacy Questionnaire (IHLQ): an instrument for measuring health literacy in Iran. Iran Red Crescent Med J. 2015;17(6):e25831. doi:10.5812/ircmj.17(5)2015.25831.

16. Peyman N, Amani M, Esmaily H. The relationship between health literacy and the theory of planned behavior on Breast Cancer Screening Programs among rural women in Roshtkhar, Iran 2015. Journal of Cellular Immunotherapy. 2015;1: 41-2.

17. Ghanbari S, Majlessi F, Ghaffari M, Mahmoodi Majdabadi M. Evaluation of health literacy of pregnant women 
in urban health centers of Shahid Beheshti Medical University. Daneshvarmed. 2012;19 (97):1-12.

18. Jovic-Vranes A, Bjegovic-Mikanovic V. Which women patients have better health literacy in Serbia? Patient Educ Couns. 2012;89:209-212. doi:10.1016/j.pec.2012.06.001.

19. Berens E, Vogt D, Messer M, Hurrelmann K, Schaeffer D. Health literacy among different age groups in Germany: results of a cross-sectional survey. BMC Public Health. 2016;16:1151. doi:10.1186/s12889-016-3810-6.

20. Bodur AS, Filiz E, Kalkan I. Factors affecting health literacy in adults: a community based study in Konya, Turkey. IJCS. 2017;10:100.

21. Bennett I, Switzer J, Aguirre A, Evans K, Barg F. 'Breaking it down': patient-clinician communication and prenatal care among African American women of low and higher literacy. Ann Fam Med. 2006;4:334-340. doi:10.1370/ afm.548.

22. Haerian A, Moghaddam MHB, Ehrampoush MH, Bazm S, Bahsoun MH. Health literacy among adults in Yazd, Iran. J Educ Health Promot. 2015;4:91. doi:10.4103/22779531.171805.

23. Sentell T, Braun KL. Low health literacy, limited English proficiency, and health status in Asians, Latinos, and other racial/ethnic groups in California. J Health Commun. 2012;17:82-99. doi:10.1080/10810730.2012.712621.
24. Brice JH, Travers D, Cowden CS, Young MD, Sanhueza A, Dunston Y. Health literacy among Spanish-speaking patients in the emergency department. J Natl Med Assoc. 2008;100:1326-1332. doi:10.1016/S0027-9684(15)31512-1.

25. Wang C, Li H, Li L, Xu D, Kane RL, Meng Q. Health literacy and ethnic disparities in health-related quality of life among rural women: results from a Chinese poor minority area. Health Qual Life Outcomes. 2013;11:153. doi:10.1186/1477-7525-11-153.

26. Schyve PM. Language differences as a barrier to quality and safety in health care: the Joint Commission perspective. J Gen Intern Med. 2007;22:360-361. doi:10.1007/s11606007-0365-3.

27. Wilson E, Chen AH, Grumbach K, Wang F, Fernandez A. Effects of limited English proficiency and physician language on health care comprehension. J Gen Intern Med. 2005;20:800-806. doi:10.1111/j.1525-1497.2005.0174.x.

28. La Vonne AD, Zun LS. Assessing adult health literacy in urban healthcare settings. J Gen Intern Med. 2008;100:1304-8. doi:10.1016/S0027-9684(15)31509-1.

29. Jovic-Vranes A, Bjegovic-Mikanovic V, Marinkovic J. Functional health literacy among primary health-care patients: data from the Belgrade pilot study. J Public Health (Oxf). 2009;31:490-495. doi:10.1093/pubmed/fdp049. 